\title{
Development of a New Construction System Hollow Malweia
}

\author{
Dr. Mahmood Shukri \\ Lecturer, Civil Engineering Department, Al-Mustansiriyah University, Baghdad, Iraq \\ mahshmah@uomustansiriyah.edu.iq
}

\begin{abstract}
This job deals with the research of one of new suspicious structures named hollow malweia. The research consists of: Research and discovery of construction method of the original solid brick structure. Creation of hollow R.C.structure based and derived from the original brick solid structure. Research and discovery of the best analytical method using staadpro 2014. Research of stress-strain condition of the R.C. hollow structure and checking the strength resistance and deflection under normal uniformly distributed loads. Give the recommendation to use or not to use the new idea.
\end{abstract}

Keywords: construction, hollow, mallweia, solid, spiral, strength

\section{Introduction}

The Great Mosque of Samarra [1] is a ninth-century mosque located in Samarra, Iraq. The mosque was commissioned in 848 and completed in 851 by the Abbasid caliph Al-Mutawakkil who reigned (in Samarra) from 847 until 861. The Great Mosque of Samarra was, for a time, the largest mosque in the world; its minaret, the Malweia Tower Fig. (1), is a spiraling cone 52 meters high and 33 meters wide with a spiral ramp [2] .The reign of al-Mutawakkil had a great effect on the appearance of the city, for he seems to have been a lover of architecture, and the one responsible for building the great Mosque of Samarra [3]. In a list of his building projects which appears in several different versions, the new Congregational Mosque and up to twenty palaces are mentioned, totaling between 258 and 294 million dirhams. The new Congregational Mosque, with its spiral minaret, built between $849(235 \mathrm{AH})$ and $851(235 \mathrm{AH})$, formed part of an extension of the city to the east, extending into the old hunting park [4]. The mosque had 17 aisles, and its walls were paneled with mosaics of dark blue glass. It was part of an extension of Samarra eastwards. The art and architecture of the mosque were influential; stucco carvings within the mosque in floral and geometric designs represent early Islamic decoration. Additionally, the mosque of Ibn Tulun in Cairo, Egypt was based on the Samarra mosque in many regards [5]. The mosque itself was destroyed in $1278(656 \mathrm{AH})$ after the Hulagu Khan invasion of Iraq. Only the outer wall and its minaret remain [6].

\section{Construction Method}

Construction method of original solid Mallweia is a result of this research. The original Mallweia was constructed via drawing a spiral the offset of which represents the width of the ladder Fig (2).

Rows of bricks were placed according to this spiral layer by layer. The new layer was constructed above the previous layer leaving indentation or offset to create the steps of the ladder. The continuity of this process created the solid Mallweia!

If we imagine that the Mallweia is opened then it will create a prismatic triangular shape the thickness of which is equal to the width of ladder Fig (2). All processes of modeling the original solid malweia are accomplished with help of autocad 2016 through this research.

\section{Purpose Of Research}

The original solid Mallweia represents invention of this land and a matter of interest, designed and constructed to be used as minaret. To develop the structure for multi-use hollow type is proposed in this research. This means wider in base to allow for the best use of internal space Fig. (1). after development the structure may be used as museum or meeting hall or other architectural purposes keeping the external shape with no change. Many questions for research appear due to this substantial modification. Some of these questions are:

1. Research of the properties of calculation by computer, to give the recommended best quick way for generating the geometry of analytical model and the necessary tricks for the computation of the structure. This will be very important for the future Ph.D. researchers to complete this job making the necessary model for experimental tests.

2. The analog of this structure with shell domes.

3. Research of the stress-strain condition to find the most critical parts of the structure and the maximum absolute stresses. Draw the contour schemes of the most critical stresses of interest. 
4. Computation of the maximum displacements and making spring analog with the computation of the stiffness of this spring if it exists.

5. Construct the relations between the thickness of walls with other parameters (deflections \& stresses) to find the recommended minimum safe economical thickness.

6. The research of the load capacity of the structure constructing the relations between loads \& other parameters.

7. Research of the effect of increasing the radius of the base with all above-mentioned parameters.

8. Research of the height \& No. Of turns of Mallweia with the parameters of interest to find the recommended size and use.

9. Research of the required reinforcement of the walls and floors of the structure.

10. Research of the construction method of the hollow type and the best structural system (steel or concrete).

11. The walls of the structure are supported on cantilever type slabs of small thickness there fore the resistance of these slabs to the weights \& loads of the upper parts is a matter of suspect. If this resistance does not exist the whole structure will collapse. This will be one of the most substantial purposes of research.

12. For this type of structures the finite elements are subjected to combined stresses (Tensile or Compressive forces (Fx or Fy) + bending moments (Mx or My) In addition to the shear forces (Qx or Qy). To judge the strength of the structure correctly these combined stresses must be taken in consideration. The elements must be designed for both bending and compression + bending and tension. Additional reinforcement must be added to the flexural reinforcement that will resist axial tension otherwise the judgment will be unsafe. This must be well researched to appreciate the structure. Not all results are shown in this research to decrease the job.

\section{Research of Construction Method of Analytical Model For Hollow Mallweia}

7 years' experience on Staadpro [12], AutoCAD [13], 2 months of successive trials with successful \& unsuccessful results enabled the researcher to complete the geometry of this shape. Due to the irregularity of structure, the repetitive facilities of the well-manufactured update software were disabled. Construction of the analytical model via manual insertion of nodes \& finite elements was simply a laborious blind job, which does not insure the generation of correct geometry. Discovery of the homogenous generation of geometry was accomplished with the help of construction method of the original solid shape Fig (2). This led to the smooth solution. Construction method of original solid Mallweia is a result of this_research. The original Mallweia was constructed via drawing a spiral. The offset of which represents the width of the ladder Fig (2).

Rows of bricks were placed according to this spiral layer by layer. The new layer was constructed above the previous layer leaving indentation or offset to create the steps of the ladder. The continuity of this process created the solid Mallweia ! If we imagine that the Mallweia is opened then it will create a prismatic triangular shape the thickness of which is equal to the width of ladder Fig (2). According to this preliminary research the process of generating the three dimensional analytical model Fig. (1) Began.

The selected model consists of Mallweia the outer radius of the base of which is equal to $12 \mathrm{~m}$. the inner radius of the base is equal to $10 \mathrm{~m}$. The difference in radius equal $2 \mathrm{~m}$ represents the width of the ladder. The total height of Mallweia is equal to $14 \mathrm{~m}$ including the upper part. No. of turns is equal to 5 . The upper part consists of hollow cylinder the height of which is equal to $4 \mathrm{~m}$. the radius is equal to $2 \mathrm{~m}$. Opening in the cylinder is inserted to represent the door via deleting the excess elements. The preliminary thickness of the walls and slabs is taken $0.15 \mathrm{~m}$.the service live loads are imposed $5 \mathrm{kN} / \mathrm{m}^{2}$

The first step in generating the geometry of structure is to draw three-dimensional spiral Fig. (2). This may be achieved using the Reverse cylindrical Coordinates of Staadpro [12]. Another three dimensional spiral is drawn also as offset to the first, the distance between the both spirals is equal $2 \mathrm{~m}$. finite elements of the floor are then added using the generation facilities of Staadpro [12] (from the editor and not the plotter). Doing so the ladder of Mallweia is generated as first step. Fig. (1). Using the same repetitive facilities, the walls of Mallweia are added to generate the major part of the structure Fig. (1).

The upper part of the structure was the most complicated. To create this part a plane spiral was constructed using the Staadpro facilities separately. This part was connected to the major part using the connect command or the paste command using (Staadpro). The dome of the upper part was added separately also using the surface of revolution of the Autocad then this drawn part was transformed in to the format of Staadpro after using the explode command and saving as dxf. file then was connected to the whole structure using the paste command. During this complicated technical process the correction of errors is quite necessary and continuos using the renumbering command of both nodes \& elements. Deleting the orphan nodes and duplicate nodes is also noticed to insure the accuracy.

The remainder part was added manually as triangular finite elements to complete the shape of Mallweia! After this complete generation the support conditions as fixed supports were imposed for the lower nodes of the structure Fig. (3). 


\section{Numerical Analysis of Hollow Mallweia}

The results of analysis of this new structure must be examined carefully and precisely. These results represent (Engineering Decision-Maker). The significance of these preliminary calculations is summarized in the following: -

If the structure can resist the external loads with the self-weight then research may be continued, if not then this proposal is considered unsuccessful structural solution the research on which is useless. To judge the structure correctly the most critical stressed finite elements were isolated making use of the sorting facilities of Staadpro. These elements have the numbers $(1,4,16,23,71,143,160)$ Fig. $(5,6)$ (calculation sheets are removed from this job). These elements have the following corresponding stresses. $\left(1=\right.$ Fy max. $\left.=1470 \mathrm{kN} / \mathrm{m}^{2}\right)$, $(4=$ My max. $=26 \mathrm{kN} . \mathrm{m} / \mathrm{m}),\left(16=\right.$ Fx max.+ $\left.=1330 \mathrm{kN} / \mathrm{m}^{2}\right),\left(23=\right.$ Fx max.- $\left.=-1180 \mathrm{kN} / \mathrm{m}^{2}\right),(71=$ Qx $\max .=467$ $\left.\mathrm{kN} / \mathrm{m}^{2}\right),\left(143=\right.$ Qy $\left.\max .=594 \mathrm{kN} / \mathrm{m}^{2}\right),\left(160=\right.$ Mx max. $\left.=-11.7 \mathrm{kN} / \mathrm{m}^{2}\right)($ sign convention Fig. (3)). It is recommended to observe the sign convention mentioned previously with the data in the calculation sheets (plate center stress summary) to appreciate the structure. It is to be noted that not only these figures are used in the judgement. Dividing the above stress figures by 1000 to convert to Mpa, we make the conclusion that these stresses are quite acceptable in comparison with the loads \& the small selected thickness of the structure $(0.15$ $\mathrm{m})$. All the wall elements are under compression as expected except element No.1 ( $F y=1470 \mathrm{kN} / \mathrm{m}^{2}$ tension) .Due to the complexity and the integrated three-dimensional effect this element was noticed to be under tension. This axial tension requires additional reinf. (\&12@0.15m approximately). Analyzing the figures we see also that the walls of the structure are subjected to shear force $(\mathrm{Qy})$ directed to the outside of the Mallweia. These shear forces must be well considered when designing the walls due to their big value. The maximum value of these forces were noticed in element No.143 $\left(\mathrm{Qy}=594 \mathrm{kN} / \mathrm{m}^{2}\right)$. This element is situated in neighbor of the upper part of the Mallweia Fig. (6). This is illustrated with the effect of the weight of the dome on the body of the structure and means that a lightweight material for this part must be selected. The maximum values of bending moments were reported for the finite elements of the walls of the first turn (at the start of Mallweia). To appreciate precisely the sense $\&$ direction of stresses it is very important to view the sequence of numbering of each finite element (I J K L). This sequence is counterclockwise Fig. $(3,5)$. If the element is so numbered then the sense \& direction of stresses \& local coordinates will be coincident with the previous figure. For the floor system i.e. slabs of the Mallweia the reported bending moments (Mx \& My) were small in comparison with the walls. The shear forces $(\mathrm{Qx})$ are too high and must be well considered specially element No.71 ( $\mathrm{Qx}=467$ $\left.\mathrm{kN} / \mathrm{m}^{2}\right)$. This value is very close to the shear Qy of wall No.143 $\left(\mathrm{Qy}=594 \mathrm{kN} / \mathrm{m}^{2}\right)$. This means that generally shear forces control the Mallweia. However the values mentioned above may be resisted by the structure according to the shear strengths checks. The significance of the correct sequent numbering of the elements and the correct generation of the structure that keep the sequence appears in this analysis. Incorrect numbering makes the process of isolating the critical elements of interest impossible or very difficult. This makes the judgment of the most critical elements and then the whole structure not safe. The size of finite elements used in the model is big but acceptable ( $2 \mathrm{X} 2 \mathrm{~m}$ approximately). In this research we were not able till now to mesh the grid i.e. use smaller elements to insure better accuracy. This unsolved problem yet needs continuity in research. The calculation sheets (27 pages not shown in this research to decrease the job) show the original computer analysis achieved on the model described previously with Total Live Loads $5 \mathrm{kN} / \mathrm{m}^{2}$ and thickness of structure equal $0.15 \mathrm{~m}$.

\section{Experiments on Mallweia}

Several experiments were achieved on the hollow type structure of Mallweia. The importance of these experiments is to show the elastic behavior of the structure under several types of conditions. Relations between the loads and deflections, loads and stresses, thickness and deflections, thickness and stresses are constructed. Several types of formulas and equations are inserted to control the behavior of the structure. From these equations (linear, polynomial, logarithmic, exponential and power). The best types of these relations that agree with the curve fitting were selected. Spring analog between the service loads (LL) and the deflection is made with the computation of the stiffness of the spring Mallweia. The load - stresses curves show the limits of loading to which this process must be stopped. The thickness - deflection and the thickness - stress shows the effect of this parameter on the others. This helps in the selecting of the best size and thickness of the structure. Experimental results of monolithic model must be added in future researches to make comparison between the theoretical and experimental results. Several additional relationships may be added to these graphs. From these relations are the relations between increasing the size of the structure and all parameters of interest. This includes the effect of the change of base radius and the increase of the height and number of turns on stresses and deflections. The importance of these relations is to find the possible size to which the Mallweia may be reached. Mathematical expressions for the spiral constructing the structure may also be added. Several mathematical relations help in generating the structure of any type and size may also be included. The graphs show that all stresses decrease with increasing the thickness except the bending moments and other flexural 
stresses, which appeared to increase with this change. The dimensions of the Mallweia must be specified and proportioned according to these relationships until the most economical safe size is selected. For the analytical model, the maximum vertical deflection was computed as $0.022 \mathrm{~m}\left(\mathrm{LL}=5 \mathrm{kN} / \mathrm{m}^{2}, \mathrm{~T}=0.15 \mathrm{~m}\right)$. Due to the irregularity of the structure, horizontal displacements were recorded also the value of which $=0.003 \mathrm{~m}$ in both directions $(\mathrm{X} \& \mathrm{Z})$. The results of all these experiments will be shown on separate research.

\section{Conclusions}

This research permits to make the following conclusions: -

1. This research belongs to the researches of new structures. It is a world well known direction in researches.

2. All the parts of this research are done in this job except the theoretical part.

3. This job suggested new hollow type structure named Mallweia, it is a new structure with new idea represents the continuity of the civilization of this land.

4. The research succeeded to proof the ability of this structure to resist the external forces including the self weight. This is a theoretical analytical proof only. The complete proof must include experimental research using reinforced concrete model. This model is not performed in this job.

5. This research succeeded to generate the analytical model for computer analysis of this irregular complicated structure with finite elements of rather big size. The finer mesh analysis to increase the accuracy was not performed due to the complexity of the structure. This process needs continuity in research.

6. The research isolated the most critical finite elements which seemed to have maximum absolute stresses of different styles ( Fx , Fy, Qx , Qy , Mx , My , Mxy , Fxy ). For the analyzed model these elements are (1, $4,16,23,71,143,160)$ Fig. $(5,6)$. These elements of great importance in the future experimental Ph.D. researches. Knowing them the places of fixing the tensors to compute the experimental strains deformations are specified.

7. Analyzing the stress-strain condition with deformations and deflections, the structure was found to be under the effect of combined stresses. The walls of the structure are subjected to axial compressive stresses in vertical direction (Fy) except some elements in the start of Mallweia. For these walls horizontal axial stresses (Fx) are compressive also except for the elements of the first turn (the start). These elements were found to be under tensile axial horizontal (tangential) stresses (see stress contours). The behavior of this complicated structure was noticed to be situated between the shell structures (pure compression) and waterretained structures. In another words some elements under tension, others under compression. The shear stresses (Qy) were recorded high in a case pushing the walls to the out side (in the radial direction). The axial compressive stresses with the confined pressure gave the explanations of the load resistance of this structure. The behavior is like the arch action in arches where the vertical loads are transformed in to axial stresses.

8. The finite elements of the floor system are subjected to combined stresses also. The shear stresses (Qx) are high in comparison with the flexural stresses (Mx, My).

9. The Mallweia is a structure governed by the shear and the axial stresses more than flexural bending stresses.

10. For the imposed initial thickness $(0.15 \mathrm{~m})$, the structure was able to resist the external imposed loads with reasonable reinforcement.

11. Special care must be given in reinforcing the start elements of the structure in the first turn. Some of these elements are under bending and axial tension. Additional reinforcement for the axial tension must be added.

12. All the elements of the Mallweia must be designed according to combined stresses (bending + tension or bending + compression). Special care must be given to shear strength checks especially in the floor system.

13. The upper part of the Mallweia (dome) contains some of the most critical elements (No.143, 160) Fig. $(5,6)$. These elements are under the effect of heavy loads of the dome. It is recommended in this research that due to this effect, lightweight structure must be selected for this part (steel) to decrease the effect of the weight.

14. Special care must be given in the generation of the analytical model for computer analysis. The floor system elements must be grouped in a separate group. The wall elements must be in another group. The upper part (dome) in third group. The generation must keep the sequence and regularity of these groups. If this process is not done carefully and precisely, the isolation of the elements for different purposes becomes impossible and as a result the analysis of the structure becomes useless. It is not possible to isolate any required element for investigation without this grouping due to the complexity.

15. The construction process of the monolithic Mallweia is possible and proofed in this research turn by turn in a procedure analog to the original solid type by constructing construction spiral. Hollow brick temporary structure may be constructed to serve as a form to the permanent reinforced structure then removed. The easiest method of construction of the Mallweia was found when the structure is selected from steel members.

16. Numerical experiments were achieved on the analytical model. These experiments included the construction of several curves and graphs. The importance of these graphs is to show the behavior of this 
structure when some of the important parameters are changed. The linear relationships show and proof the correct computer analysis of the elastic structure. They give clear picture and show the limits to which the loading process must be stopped according to the values of allowable stresses reached. 5 graphs-charts were constructed. These graphs study the change of the stresses and deformations with increase of service live loads and the thickness of the structure. Studying these curves it is obvious that the stresses are increased when the loads are increased. When the thickness is increased the deflection is decreased and all the corresponding stresses except the flexural stresses (Mx, My, Mxy). The Mallweia must be proportioned accordingly to insure the best economical safe solution.

17. For the better control of above mentioned parameters empirical formulation was inserted trying several types of equations insuring the curve fitting (linear, polynomial, logarithmic, exponential and power).

18. Spring analog was tried to relate the vertical deflection of the Mallweia with the service live loads. Stiffness of this Spring Mallweia was computed. From this relation the self-weight was deducted.

19. To construct the above curves several successive computer computations were achieved. Each marker in these curves represents one complete computer run. The importance of these equations is summarized in the previous estimate of the required value without additional computer analysis. Separate research will show these results.

20. Due to the irregularity of the Mallweia lateral deviation in displacement was noticed. The recorded value for this deviation was computed $=0.003 \mathrm{~m}$ for the analyzed model $(\mathrm{LL}=5 \mathrm{kN} / \mathrm{m} 2, \mathrm{~T}=0.15 \mathrm{~m})$. This deviation takes place in both directions (X \& Z).

21. Due to the huge work in this research some experiments mentioned in the purposes previously were not performed. From these experiments the change of the size of the structure including the bottom and the top radios with the height of the structure and number of turns. The purpose of these changes and their effect on the stresses and deformations is to find out the limits of this structure up to which the structure may reach. This will give the possible abilities and the aspects of use of this new construction system. These experiments need the construction of new models if number of turns is changed. If only the radios and the height is changed the generation of new model will not be necessary if the technique of the AutoCAD is used. This technique may modify the shape analyzed using the block command of the AutoCAD. This command allow the insertion of new model using scale factor and the explode command. The AutoCAD file may then be saved as dxf file, which may be imported by the Staadpro program.

\section{Acknowledgements}

The author would like to thank Al-Mustansiriyah University (www.uomustansiriyah.edu.iq) Baghdad-Iraq for its support in the present work.
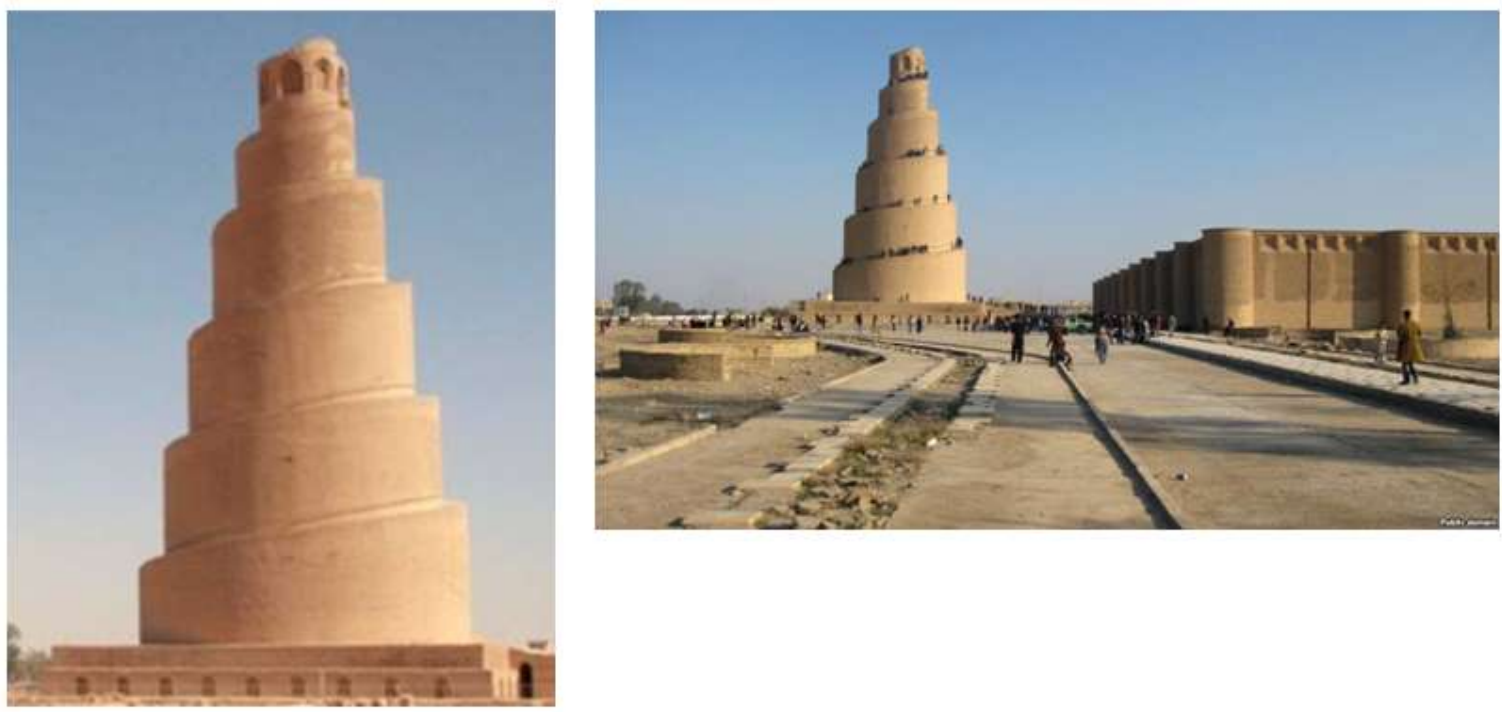

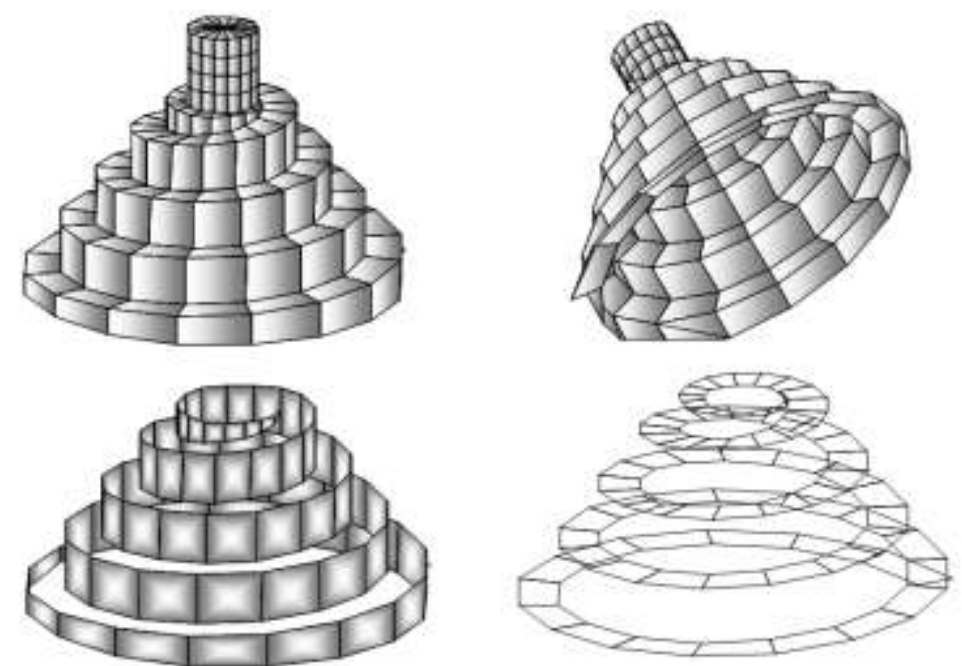

Fig. (1) Original solid malweia with the new hollow one and its generation

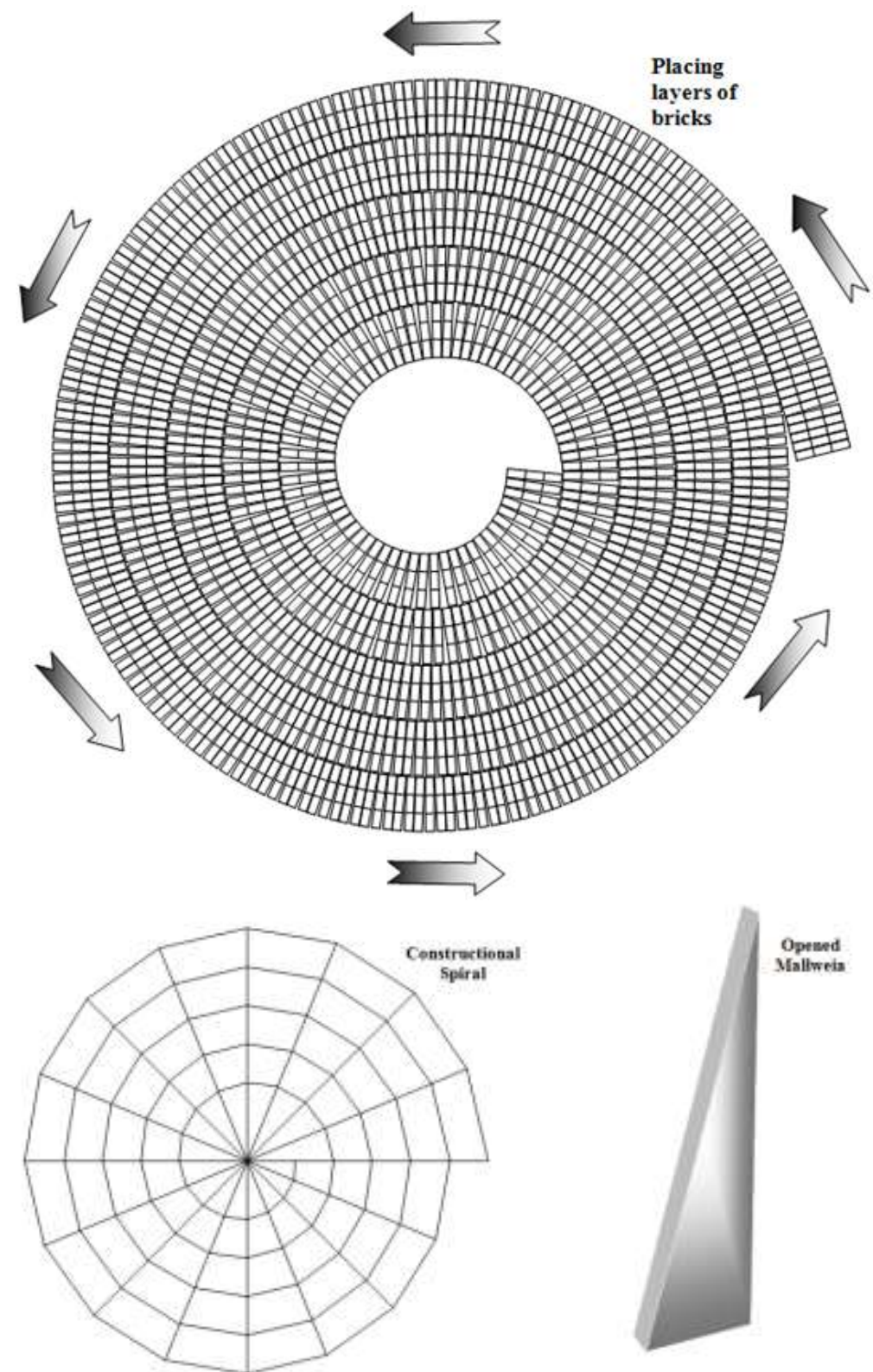

Fig. (2) The Spiral Construction Method of the Original Solid Mallweia, Result of Research 

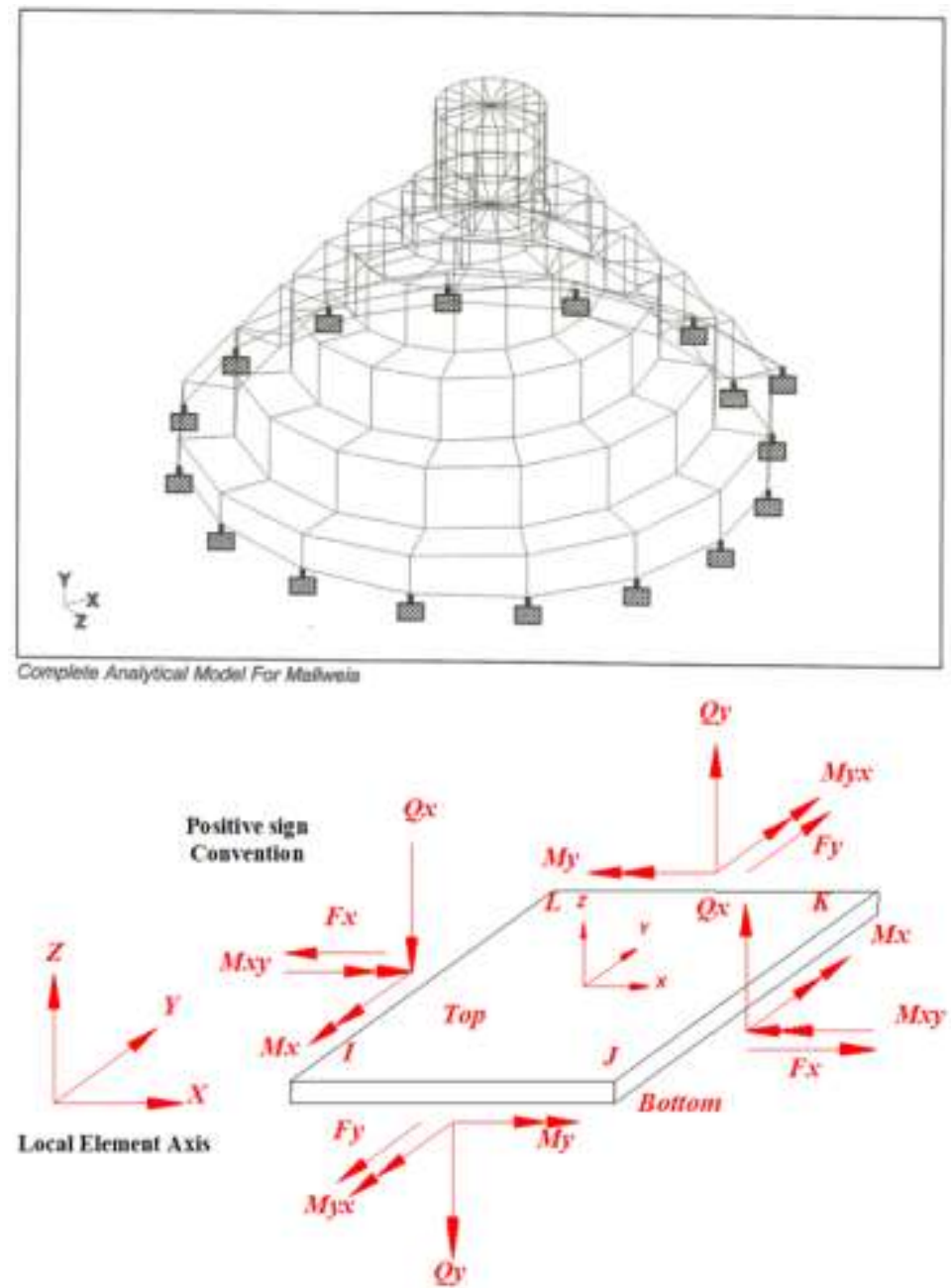

Fig. (3) Complete Analytical Model for Hollow Malweia with Sign Convention for Internal Stresses
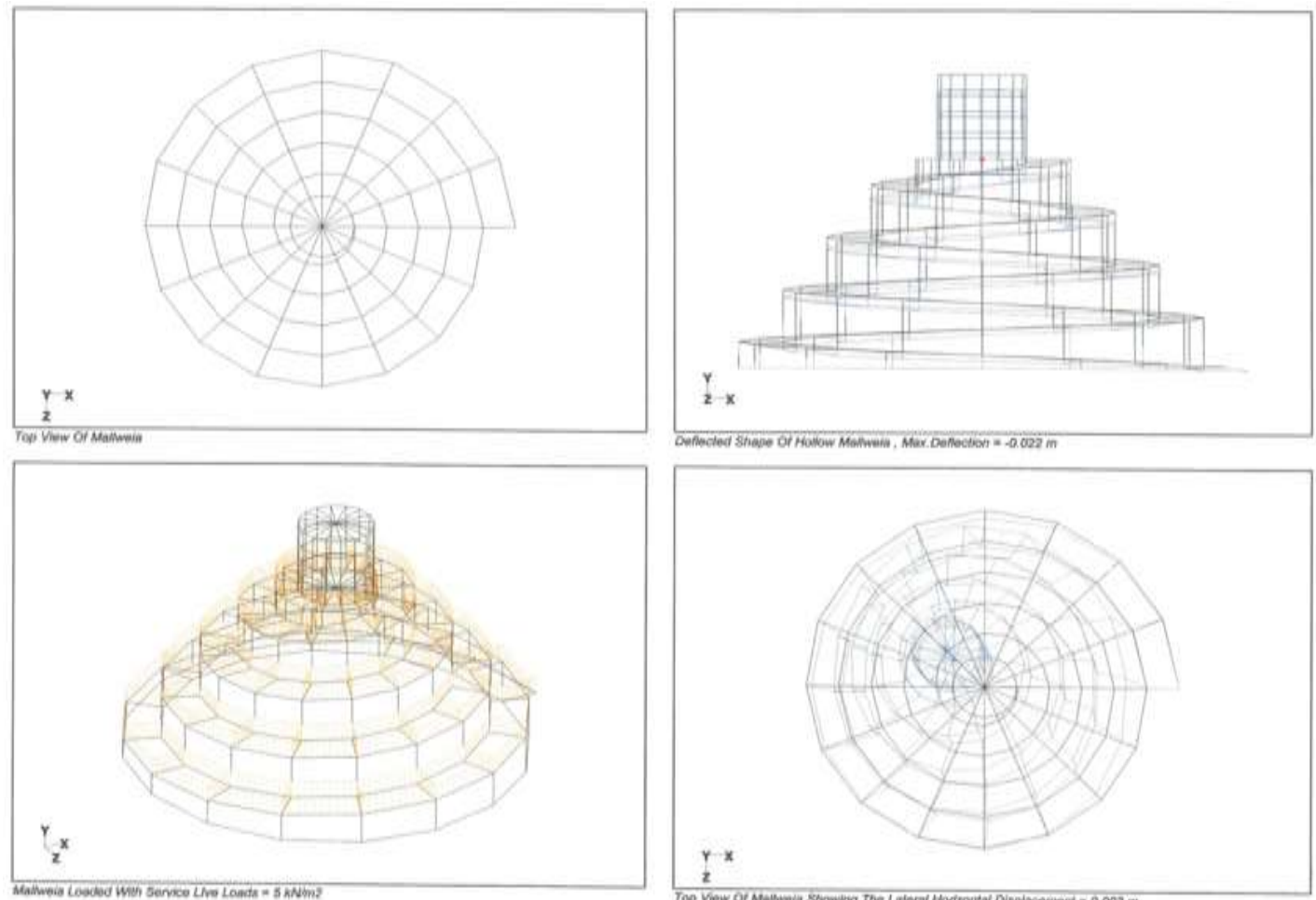

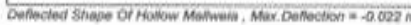

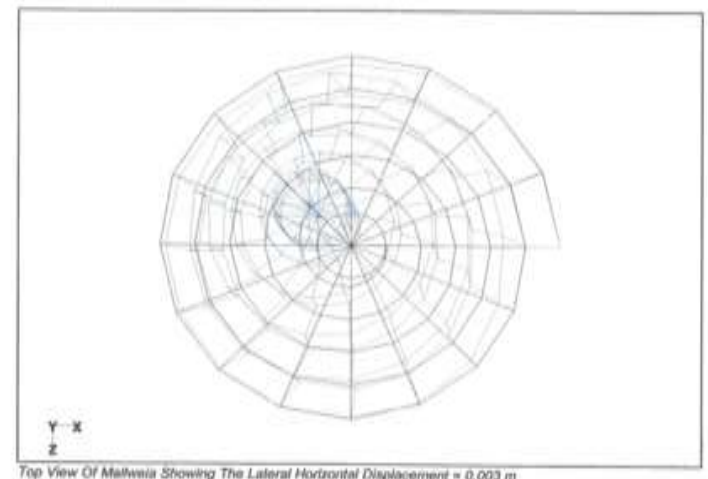



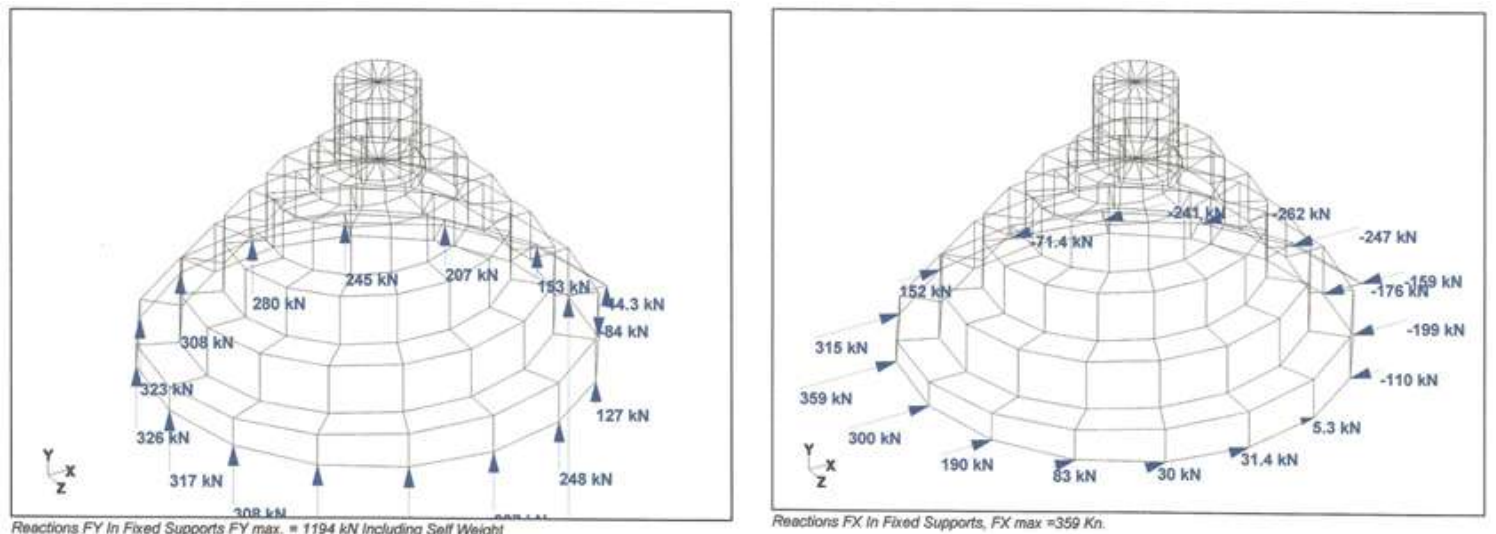

Fig. (4) Service L.L. $=5 \mathrm{kN} / \mathrm{m}^{2}$ with max.deflection $=-0.022 \mathrm{~m} \&$ max. horizontal displacement $=0.003 \mathrm{~m}, \mathrm{FY}$ max. $=1194 \mathrm{kN}$, FX $\max .=359 \mathrm{kN}$
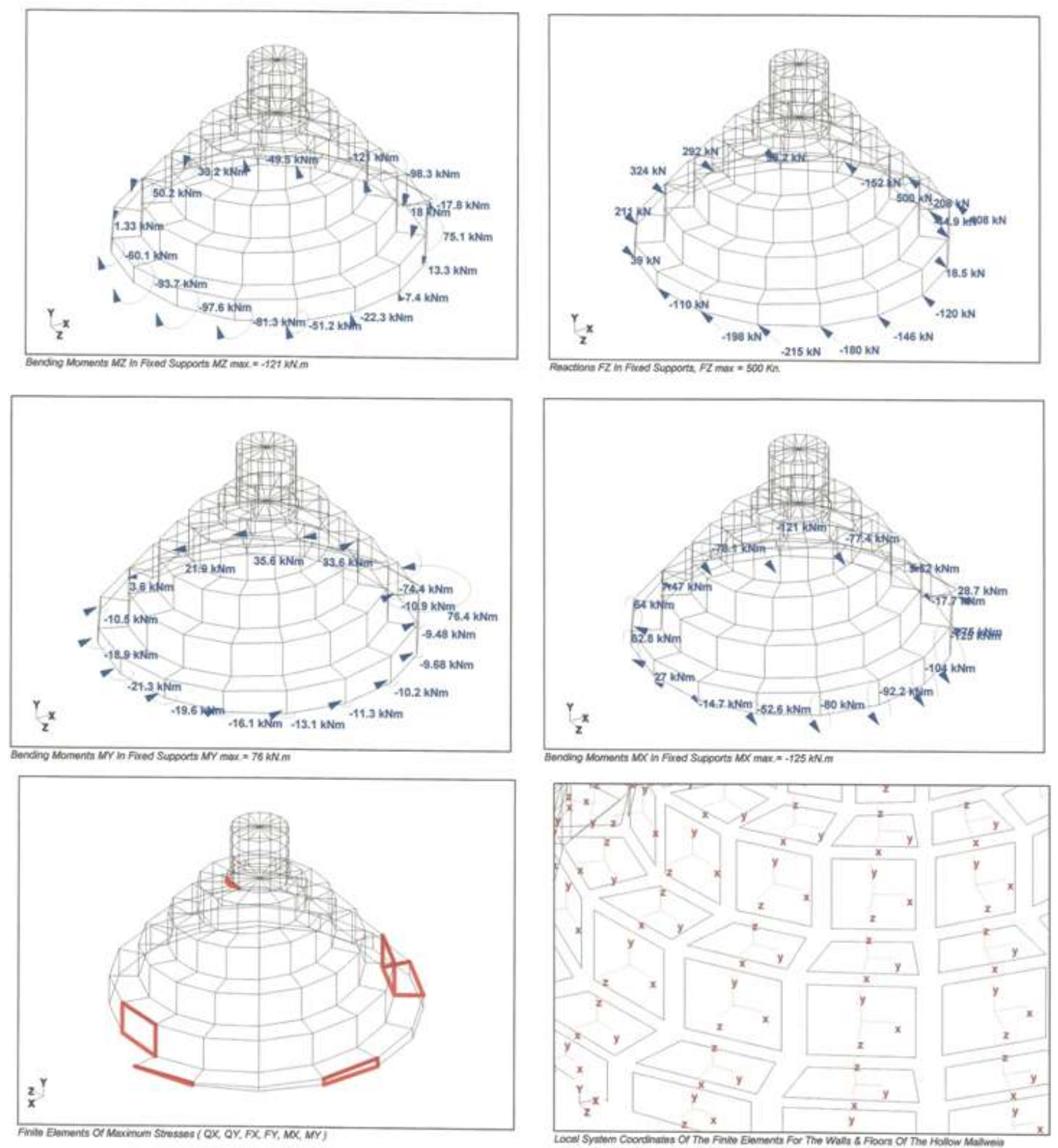

Fig. (5) MZ max. $=-121 \mathrm{kN} \cdot \mathrm{m}, \mathrm{FZ} \max .=500 \mathrm{kN}$, MY max. $=76 \mathrm{kN} \cdot \mathrm{m}, \mathrm{MX} \max .=-125 \mathrm{kN} \cdot \mathrm{m}$, Critical Elements \& local system coordinates 

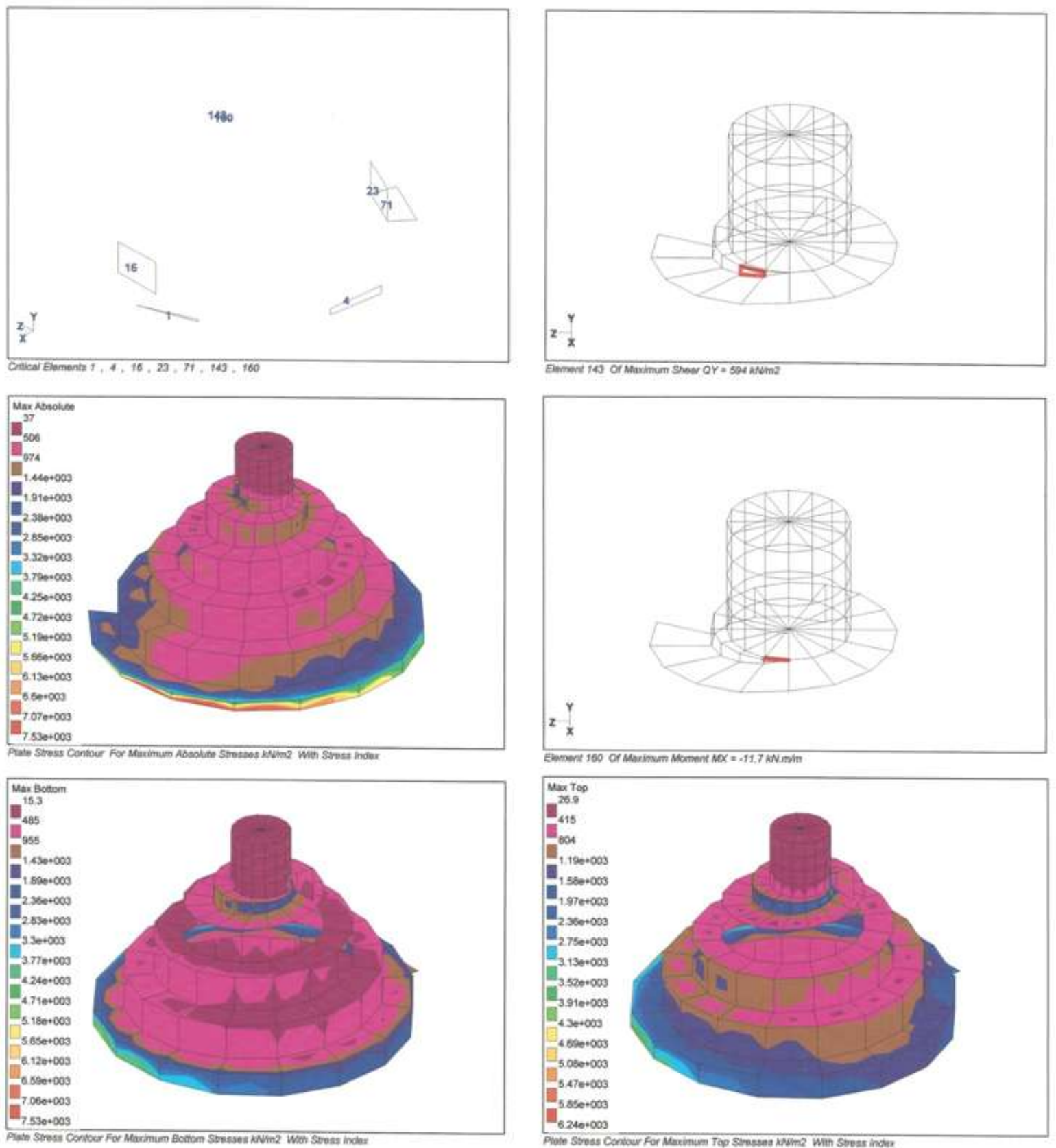

Fig. (6) isolated critical elements, QY $\max =594 \mathrm{kN} / \mathrm{m}^{2}, M X \max .=-11.7 \mathrm{kN} \cdot \mathrm{m} / \mathrm{m}$, contours for absolute stresses, max.top \& max.bottom
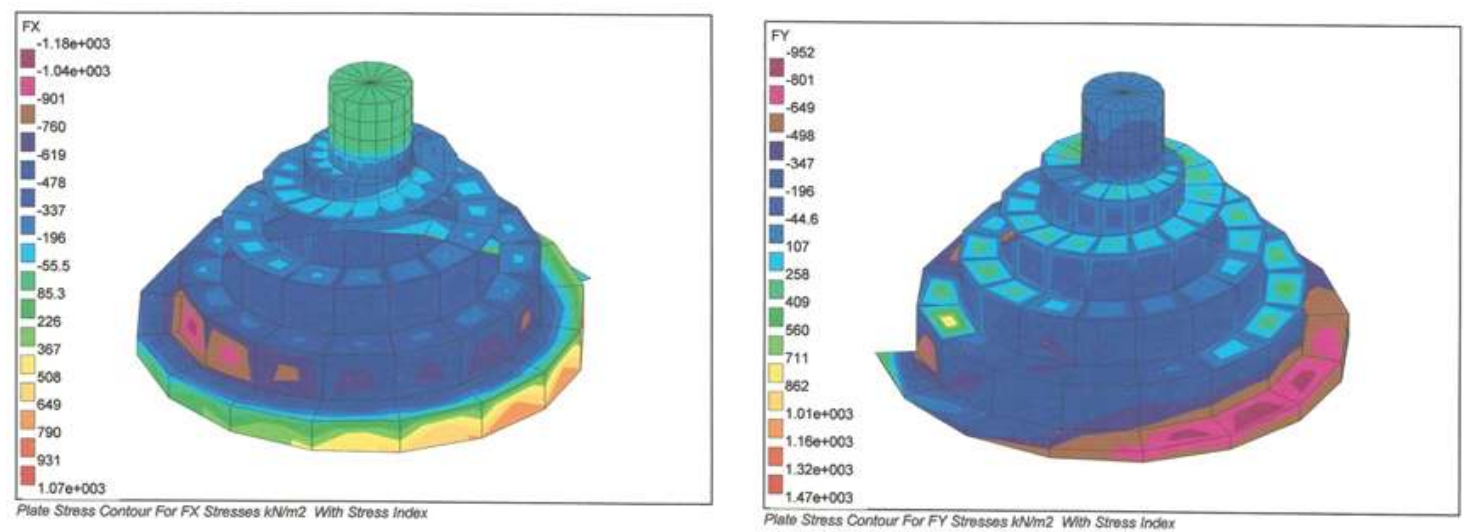

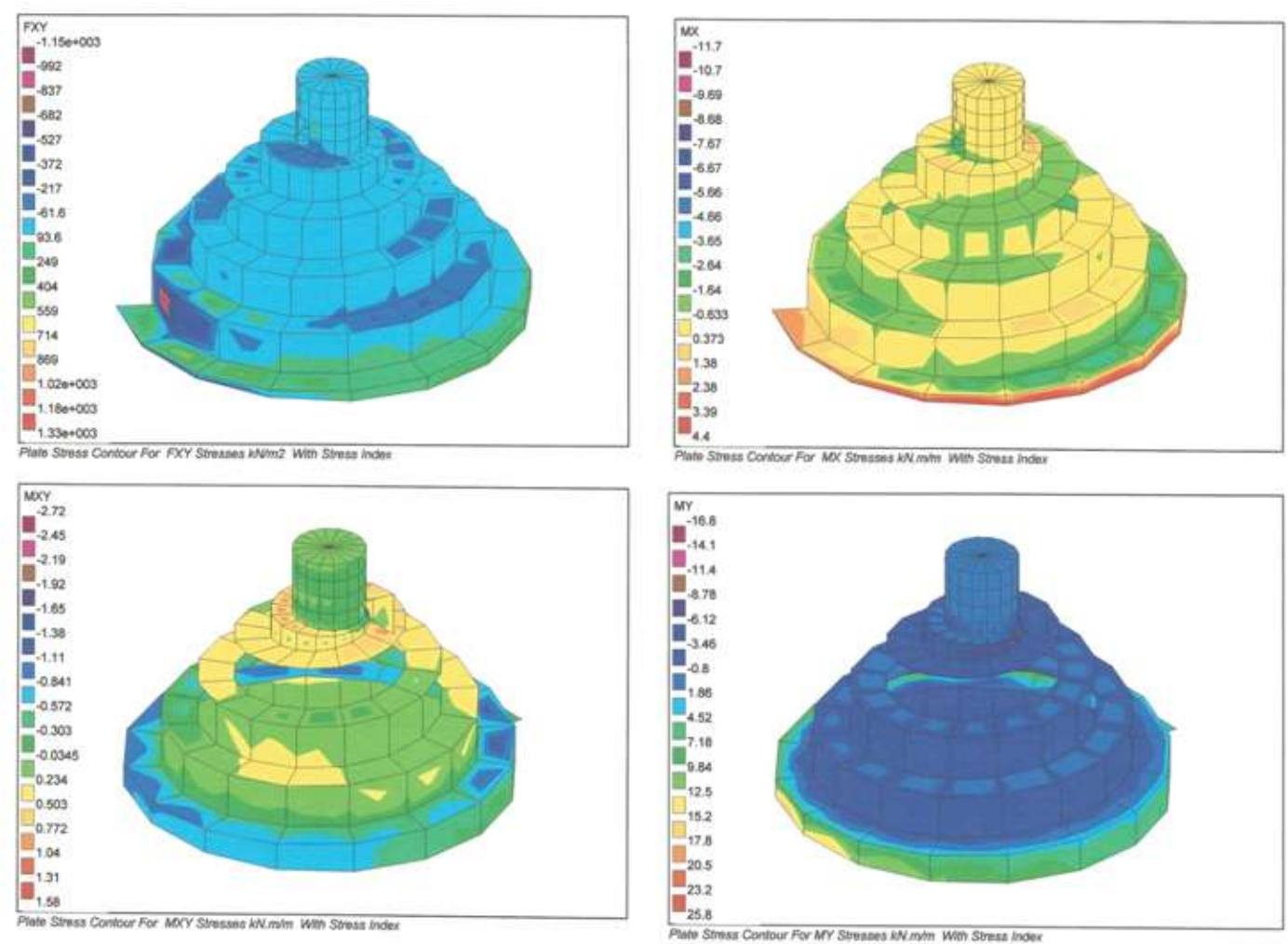

Fig. (7) Stress contours for FX, FY, FXY, MX, MXY, MY with stress index
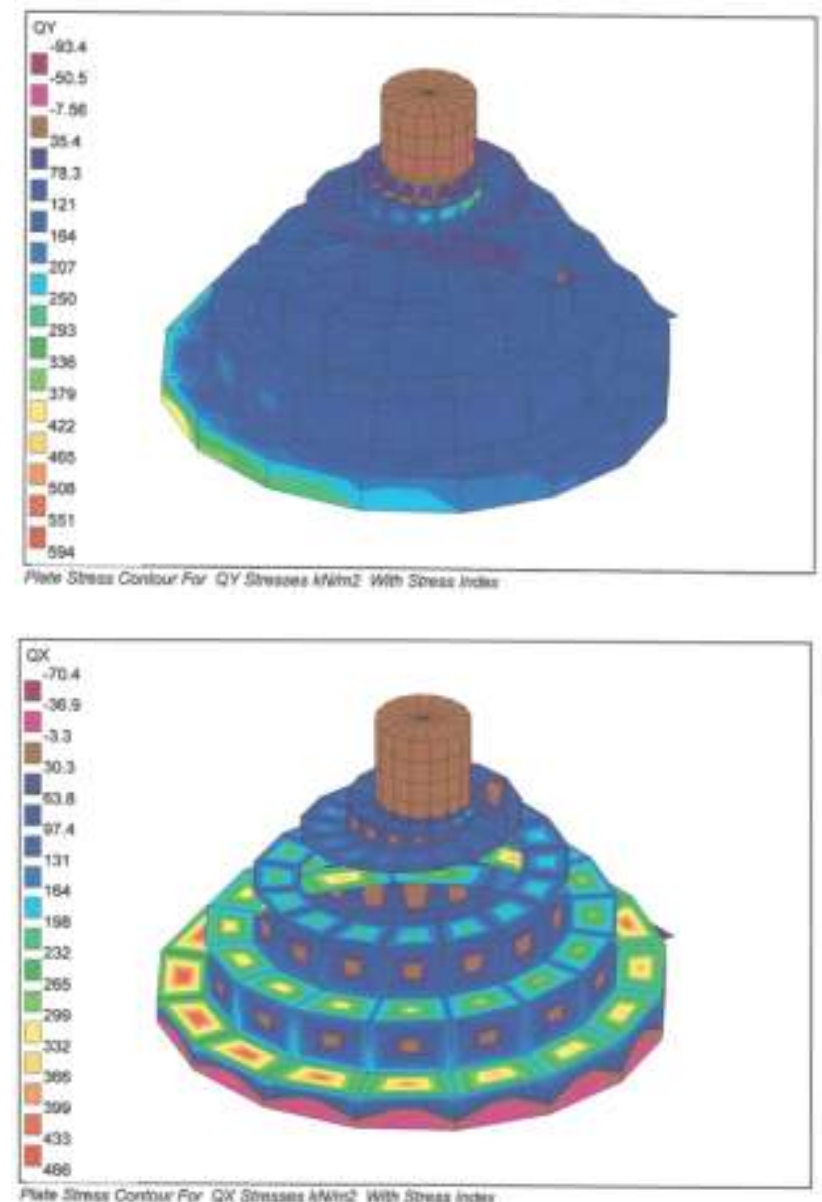

Fig. (8) Stress contours for QY, QX, kN/m2 with stress index 


\section{References}

[1] Jump up^ See Historic Mosques site.

[2] Jump up^ Dennis, Sharp (1991). The Illustrated Encyclopedia of Architects and Architecture. New York: Whitney Library of Design. p. 204

[3] Jump up^ D. Hoag., John. Islamic Architecture. Electra/Rizzoli.

[4] Jump up^ Behrens-Abouseif, Doris. "Islamic architecture in Cairo: an introduction." American University in Cairo Press: 2005. 5157

[5] Jump up^ " مسجد سامر ا ؛ برخوردار از مناره اى 53 منرى و حلزونى شكل" (in Persian). Mehr News Agency. Retrieved 27 March 2012.

[6] Jump up^ Henri, Stierlin (1977). Comprendre l'Architecture Universelle 2. Fribourg, Switzerland: Office du Livre. p. 347.

[7] $\wedge$ Jump up to: ${ }^{a b}$ Kleiner, Fred S. and Christin J. Mamiya. Gardner's Art Through the Ages: 12th edition. Thomson Wadsworth, 2005

[8] Jump up^ Kuban, Doğan (1974). "The Development of Early Mosque Architecture". The Mosque and Its Early Development. Leiden, Netherlands: Brill Publishers. p. 16.

[9] Jump up^ Kleiner, Fred (2011). "The Islamic World". Gardner's Art through the Ages: Backpack Edition, Book 3. Boston: Cengage Learning. p. 289.

[10] Jump up^ "Middle East | Ancient minaret damaged in Iraq". BBC News. 2005-04-01. Retrieved 2015-09-03.

[11] Jump up^ http://www.cemml.colostate.edu/cultural/09476/images/iraq08-02-sniper2.jpg

[12] Staadpro 2014

[13] AutoCAD 2016

[14] ACI Code 2008 